\title{
Histopathological findings in necropsy eyes with intraocular lenses
}

\author{
MARK S McMAHON, JAYNE S WEISS, KLAUS G RIEDEL, AND \\ DANIEL M ALBERT
}

From the David G Cogan Eye Pathology Laboratory of the Massachusetts Eye and Ear Infirmary, Harvard Medical School, Boston, Massachusetts, USA

SUMMARY The histopathological findings in five post-mortem eyes with anterior chamber and iris fixation intraocular lenses (IOLS) are discussed. The interval between lens insertion and death ranged from $3 \frac{1}{2}$ to 52 months. Clinically the lenses were well tolerated and the surgery was considered to be successful. In one case a vitrectomy was required. Prominent histopathological features included reduced corneal endothelium (five cases), central cornea guttata (one case), dislocation of an anterior chamber IOL (one case), abnormalities of the filtration angle (five cases), non-granulomatous iritis (two cases), and iris atrophy and erosion (five cases).

On 29 November 1949 Harold Ridley implanted the first intraocular lens (IOL).' Thirty-five years later intraocular lens implantation is a generally accepted and apparently highly successful means of improving vision after removal of a cataractous lens. ${ }^{2}$ Although examination of surgically enucleated eyes has provided some clues to the potential complications occurring with IOLs, ${ }^{3}$ a more valid assessment of their effect on the eye can be obtained by studying necropsy eyes in which an IOL has been used. ${ }^{4}$ This report describes the histopathological findings in IOL-containing eyes obtained post mortem from 1976 through 1983 at the David G Cogan Eye Path-

Correspondence to Daniel M Albert, MD, Massachusetts Eye and Ear Infirmary 243 Charles Street, Boston, Massachusetts 02114, USA. ology Laboratory of the Massachusetts Eye and Ear Infirmary. A total of five eyes were examined (Table 1).

\section{Materials and methods}

All specimens included in this study were received from the necropsy service and submitted to the David G Cogan Eye Pathology Laboratory between 1976 and 1983. Clinical data were either extracted from patient records or elicited from the patient's physicians. After measurement and gross dissection, photodocumentation was obtained for all specimens received. The IOLs were removed prior to histopathological processing as atraumatically as possible. Ten pupil-optic nerve sections were cut and stained

Table 1 Necropsy eyes after IOL implantation

\begin{tabular}{|c|c|c|c|c|c|}
\hline & \multicolumn{5}{|c|}{ Case number } \\
\hline & 1 & 2 & 3 & 4 & 5 \\
\hline Age & 90 & 74 & 89 & 71 & 89 \\
\hline Sex & $\mathbf{M}$ & $\mathbf{F}$ & $\mathbf{M}$ & $\mathbf{M}$ & $\mathbf{F}$ \\
\hline Race & $\mathbf{W}$ & W & w & W & W \\
\hline $\begin{array}{l}\text { Extraction } \\
\text { (intra- or } \\
\text { extracapsular) }\end{array}$ & $\mathrm{E}$ & I & I & I & I \\
\hline IOL & $\begin{array}{l}\text { Binkhorst } \\
\text { iris } \\
\text { fixation }\end{array}$ & $\begin{array}{l}\text { Wurst-Platina } \\
\text { iris } \\
\text { fixation }\end{array}$ & $\begin{array}{l}\text { Choyce } \\
\text { anterior } \\
\text { chamber }\end{array}$ & $\begin{array}{l}\text { Binkhorst } \\
\text { iris } \\
\text { fixation }\end{array}$ & $\begin{array}{l}\text { Medallion } \\
\text { iris } \\
\text { fixation }\end{array}$ \\
\hline $\begin{array}{l}\text { Duration } \\
\text { (months) }\end{array}$ & $31 / 2$ & $51 / 2$ & $61 / 2$ & 8 & 51 \\
\hline
\end{tabular}


with haematoxylin-eosin and periodic acid Schiff and examined independently by three observers.

\section{Results}

\section{CASE 1}

A 90-year-old white male underwent uncomplicated extracapsular cataract extraction OD with placement of a Binkhorst iris fixation IOL on 7 September 1976. His best corrected preoperative visual acuity was 20/200 OD; postoperative visual acuity was 20/50 with a normal funduscopic examination. After $3 \frac{1}{2}$ months' uncomplicated postoperative course he died of carcinoma of the lung.

Gross examination of the right eye showed a wellpositioned iris fixation IOL. A well-healed peripheral corneal scar was noted. The IOL was mechanically removed during this examination. The eye was opened in the horizontal meridian. Microscopic examination revealed a well-healed full thickness corneal scar peripherally. The endothelial cell layer was thinned and sparse. The epithelium, Bowman's membrane, stroma, and Descemet's membrane were otherwise normal. The anterior chamber was clear, and the angle appeared recessed on both sides. The iris was atrophic, with a mild chronic non-granulomatous infiltrate. Posterior synechiae to the anterior lens capsule were present. Multiple ciliary body cysts were seen. The retina showed peripheral schisis but was otherwise normal. The vitreous, choroid, sclera, and optic nerve were unremarkable.

\section{CASE 2}

A 74-year-old white female with a history of diabetic retinopathy, nephrosclerosis, and generalised atherosclerosis presented on 1 September 1976 with a best corrected visual acuity OD of finger counting at 2 feet $(60 \mathrm{~cm})$. She underwent an intracapsular cataract extraction with implantation of a Wurst-Platina iris fixation lens at this time. The procedure was complicated by vitreous loss necessitating anterior vitrectomy. Best corrected postoperative visual acuity remained at a counting fingers level consistent with the retinal changes resulting from severe diabetic retinopathy. She developed secondary glaucoma related to rubeosis and secondary angle closure postoperatively, which was successfully controlled medically. Five and a half months after cataract surgery she died of an acute myocardial infarction.

Gross examination OD revealed a well positioned iris fixation IOL. A peripheral corneal scar was noted. The retina was attached but showed extensive haemorrhages and exudates. Cobblestone degeneration was observed.

On microscopic examination of the right eye

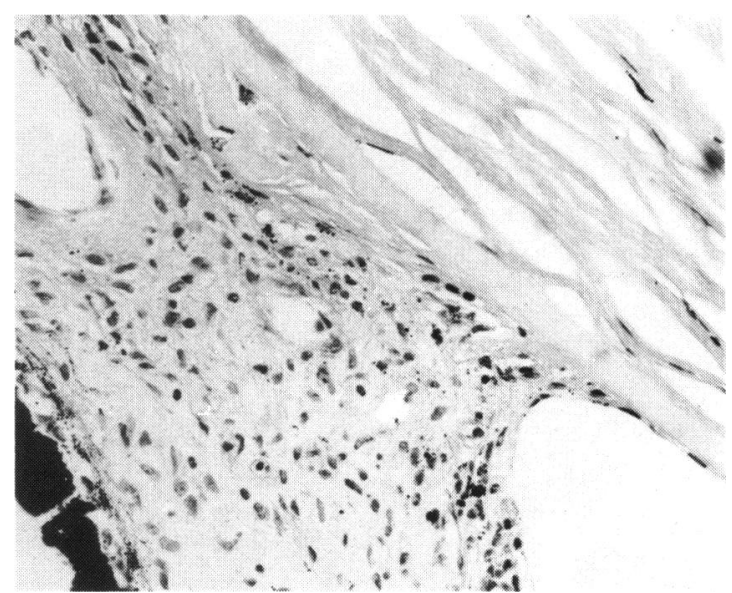

Fig. 1 Peripheral anterior synechiae in a 74-year-old diabetic female $5^{1 / 2}$ months after intracapsular cataract extraction with implantation of a Wurst-Platina iris fixation lens. (Haematoxylin and eosin, $\times 130)$.

Bowman's membrane was intact except in the area of a limbal vascular pannus. Examination of the corneal stroma revealed a well-healed surgical wound with adjacent monofilament sutures. Moderate stromal downgrowth was present near the wound. Descemet's membrane was diffusely thickened. The endothelium was scanty, with flattened cells.

The entire angle was closed by peripheral anterior synechiae adherent to the site of healed corneal sections, with prominent superficial vessels present (Fig. 1). There was minimal pigment dispersion in an otherwise normal anterior segment. Examination of the iris revealed ectropion uveae with rubeosis, as well as lacy vacuolisation of the pigment epithelium. The ciliary processes were hyalinised.

Strands of formed vitreous were observed. Examination of the retina revealed microaneurysms, deep and superficial haemorrhage, intraretinal oedema, exudates, and peripheral cystoid degeneration. No preretinal neovascularisation or retinal membrane was seen. Multiple drusen were observed. The sclera and optic nerve were unremarkable.

\section{CASE 3}

This 89-year-old white male with best corrected visual acuity of 20/200 OU presented for cataract extraction OD on 21 June 1977, at which time an uncomplicated intracapsular extraction was performed OD with insertion of a Choyce anterior chamber lens. The patient did well postoperatively. During his last eye examination four months later the lens was observed to be in place, and his visual acuity was $20 / 200$ OD. The cause of his poor visual acuity was not apparent. He died of an acute myocardial infarction $6 \frac{1}{2} 2$ months after cataract extraction. 


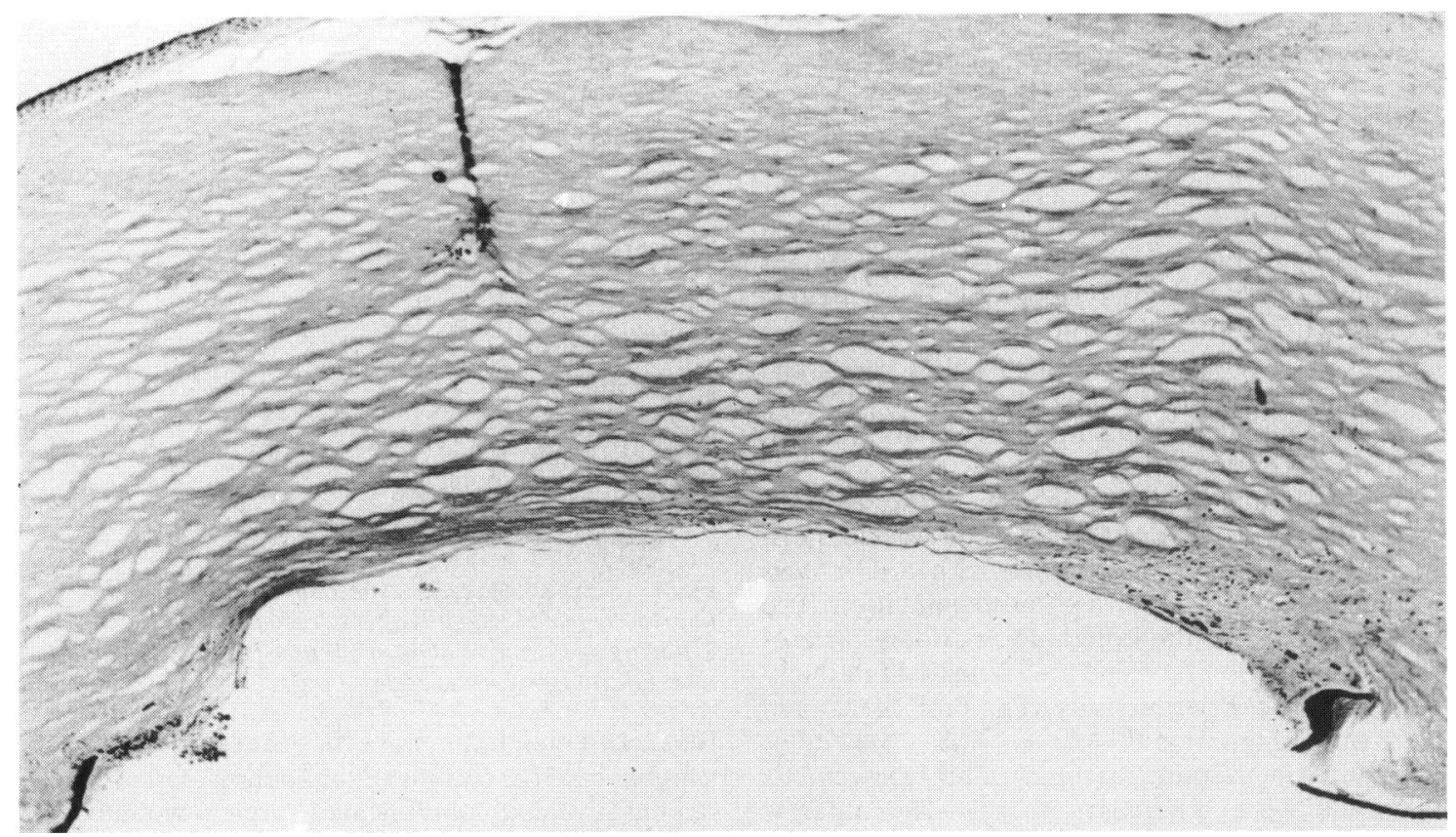

Fig. 2 Central posterior disruption of Descemet's membrane with formation of a semicircular cavity in the corneal stroma in an 89-year-old male 61/2 months after intracapsular cataract extraction with implantation of a Choyce anterior chamber lens. (Periodic acid schiff, $\times 28$ ).

A peripheral corneal scar was noted on gross examination. An IOL was mechanically removed from the anterior segment OD. The iris showed anterior synechial changes with incomplete iridectomy. The optic disc showed physiological cupping.

Microscopic examination of the cornea OD revealed a central posterior disruption of Descemet's membrane, with formation of a semicircular cavity in the stroma surrounded by chronic inflammatory cells (Fig. 2). Peripherally a well-healed stromal scar contained chronic non-granulomatous inflammatory cells, pigment granules, and suture material. An inflammatory pannus was present. The corneal endothelium was sparse, and guttae were present on Descemet's membrane (Fig. 3).

The anterior chamber was clear. The iris was atrophic and showed occasional peripheral anterior synechiae. The ciliary body was within normal limits.

The retina had peripheral cystoid degeneration but was otherwise healthy. The vitreous, choroid, and
Fig. 3 Central cornea guttata observed in case 3. (Haematoxylin and eosin, $\times 150$ ).

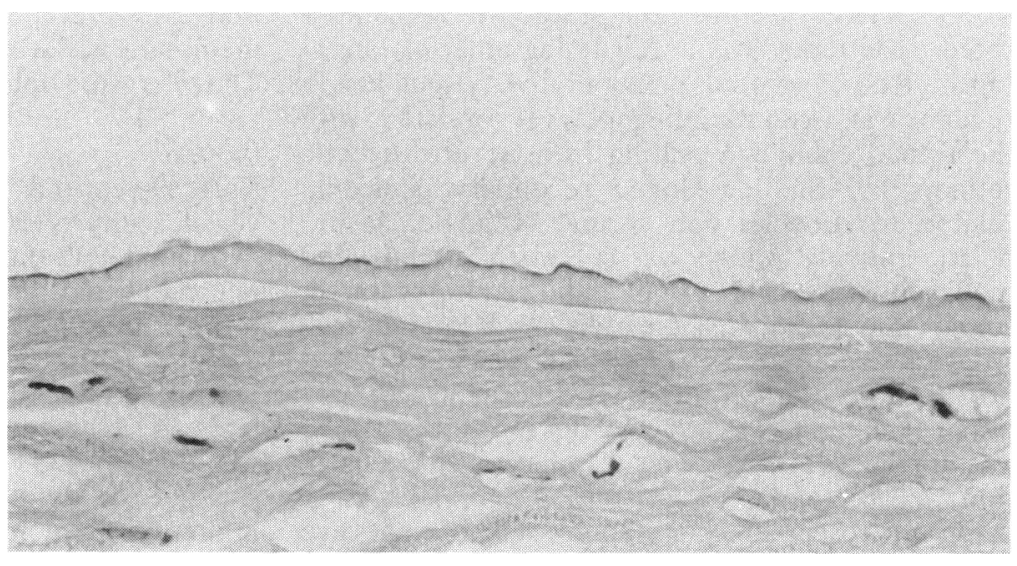




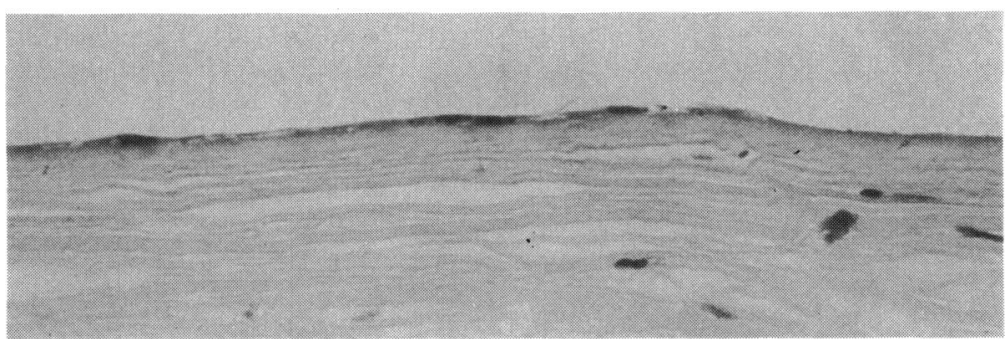

Fig. 4 A thinned and sparse endothelial cell layer was present in all eyes examined. (Haematoxylin and eosin, $\times 107)$.

sclera appeared normal. The optic nerve showed physiological cupping, with some increased cellularity, but was considered to be within normal limits.

\section{CASE 4}

A 71-year-old white man underwent an uncomplicated intracapsular cataract extraction OS with placement of a Binkhorst iris fixation IOL in September 1977. His best corrected preoperative visual acuity was $20 / 200$ OS; postoperative visual acuity was $20 / 40$ OS. After an uncomplicated course he died eight months later of respiratory failure secondary to chronic obstructive lung disease.

Gross examination of the left eye revealed a wellpositioned iris fixation IOL. A peripheral corneal scar and a large pars plana cyst were visualised. The pseudophakos was dissolved with chloroform and the haptics removed with forceps.

Microscopic examination of the left cornea revealed epithelial microcyst formation, with degenerative areas of Bowman's membrane. A fibrovascular pannus was noted peripherally. The endo- thelium was thinned and sparse, with peripheral guttae (Fig. 4).

Extracellular pigment granules were observed in the trabecular meshwork and vitreous. Examination of the iris revealed a mild chronic non-granulomatous inflammatory cell infiltrate of the stroma, focal pigment hyperplasia, areas of pigment epithelium loss, and occasional peripheral anterior synechiae. The ciliary body processes were hyalinised and contained a mild chronic non-granulomatous infiltrate.

Pigment was present on the anterior hyaloid face of the vitreous. Peripheral schisis was observed in the retina, which was otherwise normal. A mild chronic non-granulomatous infiltrate was present in the choroid. The optic nerve and sclera were within normal limits.

\section{CASE 5}

On 23 September 1976 an 89-year-old hypertensive white female with best corrected visual acuity of 20/200 OS presented for intracapsular cataract

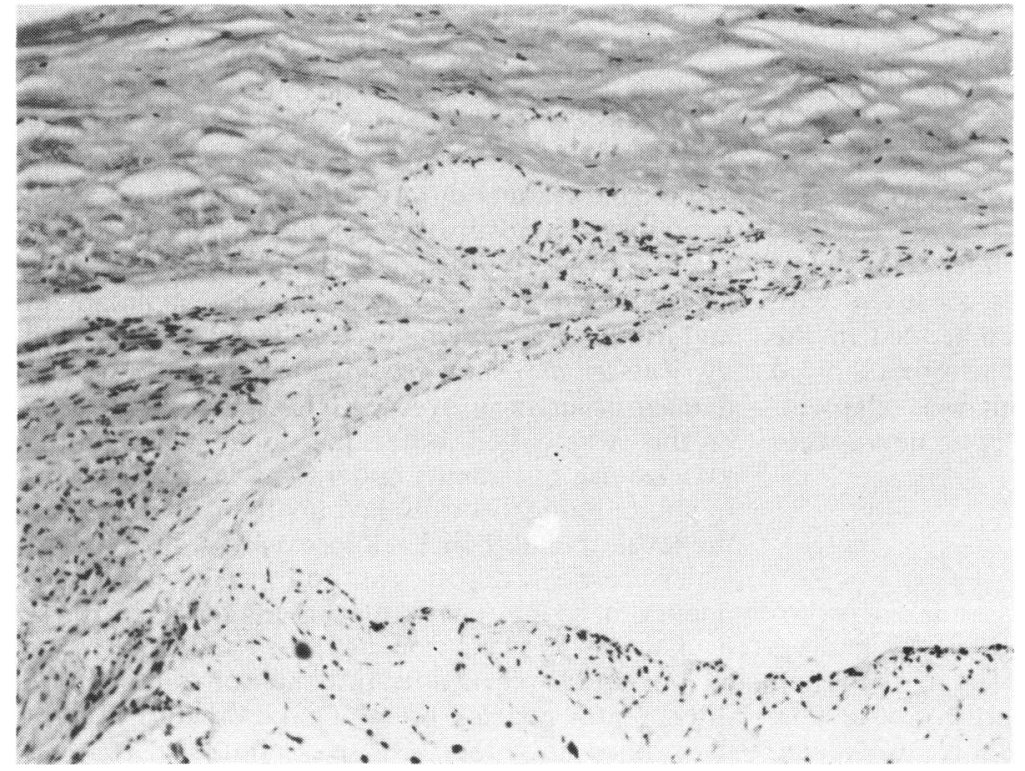

Fig. 5 Accumulation of pigment in the trabecular meshwork was commonly observed and is thought to be secondary to iris pigment erosion and dispersal. (Haematoxylin and eosin, $\times 67$ ). 
Fig. 6 Erosion of iris pigment epithelium caused by an iris supported Medallion lens. (Haematoxylin and eosin, $\times 40$ ).

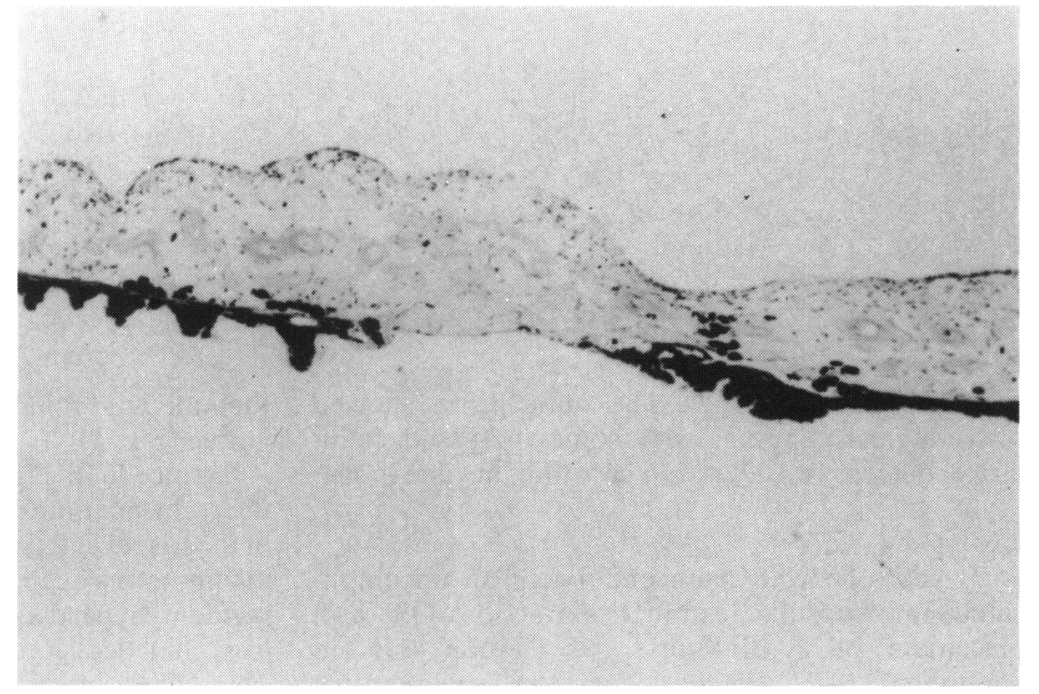

tic histopathological assessment of this procedure comes from the findings based on the examination of necropsy eyes in which an IOL has been used. From the post-mortem findings it would seem that intraocular lenses are well tolerated by the eye so long as there have been no clinical complications. ${ }^{5}$ Wolter $e t$ al. ${ }^{6}$ point out that, 'from the viewpoint of the eye pathologist', eyes with IOLs are 'not normal'-but are also 'certainly not sick.' The consequences of IOLs which we have observed in our series of postmortem eyes include apparent endothelial loss, central cornea guttata, IOL dislocation, abnormalities of the filtration angle, iritis, and iris atrophy and erosion.

The corneal endothelium in these eyes shows variable degrees of cell loss and thinning. Endothelial cell loss is a common accompaniment of intraocular lens insertion and has frequently been attributed to intraocular trauma during lens implantation as well as non-specific adverse effects related to the presence of an IOL. ${ }^{7-9}$ With sufficient endothelial damage corneal deturgescence can no longer be maintained, and irreversible oedema occurs. The data presented by Rao et al. ${ }^{9}$ show progressive endothelial cell damage occurring in eyes with IOLs. In his discussion of this article Leibowitz ${ }^{9}$ questioned whether the average age of patients undergoing intraocular lens implantation statistically favours their death before the level of endothelial cell loss reaches the point at which corneal decompensation occurs. The frequency of persistent corneal oedema after intraocular lens implantation has been reported to be $6 \cdot 2 \% .{ }^{10}$ In fact corneal transplantation is now more often performed for pseudophakic bullous keratopathy than any other disease. Endothelial cell loss bias by virtue of the fact that the eyes came to enucleation. An additional and probably more realis- 
has been claimed to be much less severe in eyes with posterior chamber lenses than in eyes with anterior chamber, iris fixation, or iridocapsular lenses."

The histopathological findings in case 3 are compatible with a partial penetrating injury to the central cornea by the anterior chamber lens. Cameron and Doughman ${ }^{12}$ point out that, if mechanical compression on a tissue by an IOL is severe or prolonged or if the fibroproliferative response to the tissue is inadequate, the synthetic material will appear to migrate through the tissue, with resultant erosion. The IOL in this case was last observed in place by an ophthalmologist three months prior to the death of the patient. The dislocation rate of all IOLs has been reported to be about $4 \% .{ }^{13}$ Iris fixation lenses are known to become dislocated following pupil dilatation." 1314 However, because this patient had an anterior chamber IOL, the role of trauma or a poor fitting IOL should be considered in the aetiology of the dislocation. While luxation into the anterior chamber can produce corneal dystrophy or erosion, dislocation of an IOL into the vitreous cavity can result in macular degeneration or retinal detachment, as well as vitreous loss secondary to surgical attempts at retrieval of the IOL.

Abnormalities of the filtration angle were observed in all cases and included pigment in the trabecular meshwork, angle recession, and angle closure. The cause of the glaucoma in case 2 is difficult to determine. Whether glaucoma was secondary to the vitreous loss or to the presence of an IOL cannot be assessed. Glaucoma has been reported to be responsible for from $21 \%{ }^{15}$ to $59 \%{ }^{16}$ of enucleations following cataract surgery with IOLs. While cases 3,4 , and 5 showed signs of pigment dispersion to the trabecular meshwork, these eyes did not develop clinical evidence of glaucoma. Angle recession such as that described in case 1 is believed to occur with anterior chamber IOLs owing to erosion of haptics into the ciliary body. Angle recession often precedes secondary glaucoma because Descemet's membrane and the endothelium gradually extend over the recessed angle and eventually impede aqueous outflow. Peripheral anterior synechia formation, observed in cases 2,3 , and 4 , is the most frequent pathogenic mechanism resulting in glaucoma following cataract surgery. $\mathrm{Jaffe}^{14}$ identifies delayed formation of the anterior chamber as the commonest cause of peripheral anterior synechiae.

Our observation of non-granulomatous chronic inflammation of the iris in cases 1 and 4 is consistent with numerous previous reports describing nongranulomatous iritis with IOLs. ${ }^{6}{ }^{17-19}$ Although the infiltration was located at the site where the lens had been in contact with the iris stroma, it is unclear whether the inflammatory process was due to mechanical and/or toxic irritation. In none of the patients was the iritis sufficiently severe to produce clinical symptoms. It is of note that Kincaid et al. . $^{5}$ have described a conspicuous granulomatous reaction on the anterior iris surface in a post-mortem eye with a well-tolerated anterior chamber lens. No evidence of this was observed in this series.

Iris atrophy and erosion were common findings. Focal loss of pigment epithelium was observed, with dispersal of pigment to the anterior chamber, vitreous, corneal wound, and trabecular meshwork. Iris atrophy and erosion are believed to be due to surgical trauma and to mechanical pressure and friction by the IOL. ${ }^{19}$ McDonnell et al. ${ }^{11}$ have reported that iris atrophy and erosion can be consistent with excellent visual acuity. They note that iris change is not often seen with posterior chamber lenses.

From post-mortem findings it would appear that IOLs are well tolerated by the eye. Although uniform clinical success was achieved in this series after pseudophakos implantation, all necropsy eyes showed histopathological consequences of the insertion and continuing presence of the IOL. The corneal endothelium in all eyes examined showed variable degrees of cell loss and thinning; central cornea guttata was noted in one case. Abnormalities of the filtration angle were observed in all cases and included pigment in the trabecular meshwork, angle recession, and angle closure. There were two cases of non-granulomatous chronic iritis and five cases of iris atrophy and erosion. Histopathological changes in an eye with an anterior chamber IOL were compatible with a partial penetrating injury to the central cornea. Cystoid macular oedema, reported to occur in from $5 \%^{21}$ to $44 \%^{21}$ of eyes with IOLs, was not observed in this study. Although the lenses were well tolerated, increased information can be afforded by histopathological examination of post-mortem eyes containing IOLs. The correlation between histopathological findings and type of IOL will help us to draw conclusions on the optimal type of IOL that should be used.

\section{References}

1 Ridley H. Intra-ocular acrylic lenses. Trans Ophthalmol Soc UK 1951; 71: 617-21.

2 Stark WJ, Worthen DM, Holladay JT. The FDA report on intraocular lenses. Ophthalmology 1983; 90: 311-7.

3 Spencer WH. Symposium: Complications of modern surgical procedures. Introduction. Ophthalmology 1978; 85: 115.

4 Curtin VT. Cases presented at the joint Verhoeff Society and European Ophthalmic Pathology Socicty Meeting. Washington, DC. April 1976.

5 Kincaid MC, Green WR, Iliff WJ. Granulomatous reaction to Choyce style intraocular lens. Ophthalmic Surg 1982; 13: 292-9.

6 Wolter JR, Croasdale RE, Bahn CF. Reactions to an anterior 
chamber lens two years after implantation. Ophthalmic Surg 1980; 11: 794-800.

7 Bourne WM, Kaufman HE. Endothelial damage associated with intraocular lenses. Am J Ophthalmol 1976; 81: 482-5.

8 Hirst LW, Snip RC, Stark WJ, Maumenec AE. Quantitative corneal endothelial evaluation in intraocular lens implantation and cataract surgery. Am J Ophthalmol 1977; 84: 775-80.

9 Rao GN, Stevens RE, Harris JK, Aquavella JV. Long-term changes in corneal endothelium following intraocular lens implantation. Ophthalmology 1981 ; 88: 386-97.

10) Berkowitz P. Orton RB, Boyaner D, Brownstein S. Pscudophakic bullous keratopathy; a clinical-pathologic analysis. Can J Ophthalmol 1979; 14: 3-9.

11 McDonnell RJ, Green WR, Maumence AE, Iliff WJ. Pathology of Intraocular lenses in 33 eyes examined postmortem. Ophthalmology 1983; 90: 386-403.

12 Cameron JD, Doughman DJ. Transcorneal extrusion of an intraocular lens. Ophthalmology 1983; 90: 404-9.

13 Drews RC. Inflammatory response, endophthalmitis, corneal dystrophy, glaucoma, retinal detachment, dislocation, refractive crror, Iens removal, and enucleation. Ophthalmology 1978; 85: $164-75$.
14 Jaffe NS. Cataract surgery and its complications. St Louis: Mosby, 1981.

15 Mauricllo JA, McLcan IW, Wright JD. Loss of eyes after intraocular lens implantation: a clinicopathologic study. Ophthalmology 1983; 90: 378-85.

16 Bresnick GH. Eyes containing anterior chamber acrylic implants: pathologic complications. Arch Ophthalmol 1969; 82: 726-37.

17 Ashton N, Choyce DP. Pathological cxamination of a human eye containing an anterior chamber acrylic implant. BrJ Ophthalmol 1959; 43: 577-83.

18 Ashton N, Boberg-Ans J. Pathology of an aphakic cye containing an anterior chamber implant. Br J Ophthalmol 1961; 45: 543-9.

19 Manshot WA. Histopathology of eyes containing Binkhorst Ienses. Am J Ophthalmol 1974; 77: 865-71.

20 Pearce JL. Long-term results of the Binkhorst iris clip lens in senile cataract. Br J Ophthalmol 1972; 56: 319-31.

21 Winslow RL, Taylor BC, Harris WS. A one-year follow-up of cystoid macular edema following intraocular lens implantation. Ophthalmology 1978; 85: 190-6. 